\title{
A comparison of the Australian and Tokyo Emissions Trading Schemes
}

Associate Professor Justin Dabner, Law School, James Cook University, Cairns, Australia; Adjunct research fellow in Business Law and Taxation, Faculty of Business and Economics, Monash University, Australia

Justin.Dabner@jcu.edu.au

Dr Justin Dabner's area of specialisation is primarily comparative international tax having previously been the National Tax Technical Director for both Deloitte Touche Tohmatsu and Ernst and Young. He has extensively toured South East Asia working on research projects, undertaken research in the Pacific island state of Vanuatu, New Zealand, the United Kingdom and South Africa and has previously been seconded to the Tax Policy Institute at Kansai University in Osaka, Japan. During 2012/13 he was appointed as the visiting professor in Australian studies at Tokyo University. 


\title{
A comparison of the Australian and Tokyo Emissions Trading Schemes
}

\section{Key words}

Climate change, emissions trading schemes, Australia, Tokyo

\begin{abstract}
As part of its response to climate change the 1997 Kyoto Protocol envisages the employment of emissions trading schemes ("ETS") to provide a market based incentive to reduce emissions and to engage in carbon sequestration activities. Such schemes would also serve to encourage the creation of an industry focused on energy conservation and alternatives to energy production - so called "green” or “clean” energy.
\end{abstract}

Whilst a number of jurisdictions have introduced ETSs there is no definitive model. In 2010 the Tokyo Metropolitan Government (“TMG”) established an ETS and currently Australia has had a comprehensive nationwide regime in place since 1 July 2012. Notably the approaches adopted in the two jurisdictions have marked differences.

It is proposed to compare the two regimes with a view to identifying lessons for ETS design and implementation. 


\section{A comparison of the Australian and Tokyo Emissions Trading Schemes}

\subsection{Introduction}

Pursuant to the Kyoto Protocol ${ }^{1}$ developed countries collectively committed to reduce greenhouse gas emissions by at least 5\% below 1990 levels during 2008 to 2012. A core element of the Protocol was that a price should be set on greenhouse gas emissions.

A primary mechanism to achieve this price was to be national emissions trading schemes ("ETS") that might ultimately be linked thereby establishing a global market. A number of jurisdictions have now implemented ETSs. For example, the European Union ("EU”) implemented an ETS in 2005, New Zealand in 2008, the Tokyo Metropolitan Government (“TMG”) in 2010, Australia in 2012 and California from 2013.

Whilst the current Australian Government proposes to repeal the Australian ETS effective 1 July 2014 this decision is premised on an opposing philosophical perspective rather than a concern with the operational elements of the ETS. Essentially the Government is proposing that Australia should achieve its emissions reductions through taxpayer funded programs rather than using market forces.

Meanwhile the TMG regime is being promoted as a blueprint for other sub-national jurisdictions, including Sydney. ${ }^{2}$

It is proposed to compare the features of the two regimes with a view to identifying any lessons for ETS design.

\subsection{The Australian ETS}

The Australian ETS became effective 1 July 2012. ${ }^{3}$ The ETS operates as a fixed price regime until 1 July $2014^{4}$ by which time it was intended that emissions caps would be imposed and trading expected to commence. The rationale for this reflected a view that Australia needed to be part of a global market for carbon permits that the then Government hoped would exist by 2014.

\footnotetext{
${ }^{1}$ To the United Nations Framework Convention on Climate Change available at www.unfccc.int (last visited 5 October 2012).

2 “Tokyo. The World's carbon markets: a case study guide to emissions trading” Environmental Defense Fund, International Emissions Trading Association, September 2013 available at http://www.edf.org/sites/default/files/EDF_IETA_Tokyo_Case_Study_September_2013.pdf (last visited 4 March 2014). ("IETA Tokyo")

3 See http://www.climatechange.gov.au/media/whats-new/clean-energy-legislative-package.aspx (last visited 11 November 2012). For discussion and analysis see: Rosemary Lyster, “Australia's Clean Energy Future Package: Are we there yet?” (2011) 28 (6) Environmental and Planning Law Journal 446 and Murray Wilcox and Michael Rennie, Australian emissions trading law, Thomson Reuters 2012.

${ }^{4}$ The unit price is fixed until 1 July 2014, for the first year at AUD\$23 per tonne and then rising at 2.5\% pa in real terms, purchased from the Government and immediately surrendered. Note that the date was brought forward from 1 July 2015 as initially proposed.
} 
Interim operation as a fixed price avoided the potential for price volatility, a strong possibility given the small size of the Australian domestic market, with its potential negative impact on achieving behavioral change and encouraging investment in green energy technology.

This hybrid nature of the regime required the Government to set the initial price. This exercise involved a tradeoff between environment integrity and cost containment. Business interests referred to the price at which carbon permits were trading in Europe (then around AUD\$15) whilst environmentalists pointed to analysis that suggested a price around AUD\$130 was necessary to drive investment in renewable energy. Ultimately the price of AUD\$23 for the first year was selected as a compromise.

The relevant features of the regime, including the future elements now in doubt, ${ }^{5}$ can be outlined as follows: ${ }^{6}$

- $\quad$ The top 294 "large" emitters of carbon dioxide are to purchase an eligible emissions unit (“EEU”) per tonne of carbon dioxide emitted each year from facilities over which they have operational control (with no cap imposed until 2014). 7 "Large" emitters are entities that emit 25,000 metric tonnes ${ }^{8}$ or more of carbon dioxide annually (or the equivalent) ${ }^{9}$ with entities required to calculate emissions and be subject to audit.

- $\quad$ Those entities affected are to report carbon emissions for a financial year to the Clean Energy Regulator ${ }^{10}$ ("CER") whose function is to ensure the accuracy of these reports and impose penalties if insufficient EEUs are purchased. ${ }^{11}$ Whilst the compliance year ends 30 June, the requisite units are not required to be surrendered until 1 February in the following year (at least under the fixed price regime).

- $\quad$ From 1 July 2014 the fixed price EEUs would be replaced by a “cap and trade” ETS with annual caps on emissions to be set five years in advance. That is, in 2014 caps would be set for the first five years of the ETS with the caps extended each year after the scheme commences.

\footnotetext{
${ }^{5}$ A new Coalition Government elected in September 2013 has tabled legislation repealing the current ETS effective 1 July 2014 prior to the trading mechanism commencing.

${ }^{6}$ A detailed summary of the legislation and surrounding issues is available in the Bills Digest no. $682011-12$ available at http://www.aph.gov.au/Parliamentary_Business/Bills_Legislation/bd/bd1112a/12bd068 (last visited 11 November 2012).

${ }^{7}$ Some businesses not liable under this scheme are subject to an equivalent carbon price through reductions to fuel tax credits arrangements. Whilst the Government estimated that around 60\% of Australia's emissions would be covered by the ETS with other measures there is a carbon price effectively imposed on 2/3rds of all emissions: Australian Government, Carbon pricing mechanism: who is liable?, available at http://www.cleanenergyfuture.gov.au/500-companies/ (last visited 6 March 2013).

${ }^{8}$ Some landfill operators emitting 10,000 tonnes or more and certain natural gas retailers are also caught.

${ }^{9}$ The ETS applies to four of the six greenhouse gases acknowledged in the Kyoto Protocol.

${ }^{10}$ By 31 October.

${ }^{11}$ Initially at $130 \%$ of the cost of acquiring an EEU. Under the market mechanism the charge would be double the average price of units for the year.
} 
- $\quad$ Limited borrowing of EEUs from future years would be permitted. A liable entity would be able to borrow up to $5 \%$ of EEUs from future years and use those EEUs to meet their current year liability.

- $\quad$ Unlimited banking of EEUs would be allowed. ${ }^{12}$

- $\quad$ EEUs would be allocated by auction in most cases. No EEUs from the fixed price period could be carried over to the full ETS.

- Australian Carbon Credit Units (“ACCU”) could be used to satisfy emissions obligations. ${ }^{13}$ ACCUs are generated through certain farming and forestry activities known as the carbon farming initiative. ${ }^{14}$

- $\quad$ Emissions intensive trade exposed (“EITE”) industries (such as steel, aluminum, zinc and glass production) receive substantial assistance in the form of free units, covering up to $94.5 \%$ of their liability during the fixed price period. Free EEUs were also issued to coal-fired electricity and gas suppliers ${ }^{15}$ and tax cuts, pension increases and other compensatory government payments were implemented by way of household assistance. $^{16}$

- $\quad$ The agricultural sector is exempted. Gasoline is also exempted but large diesel and jet fuel users were subject to increases in excise taxes. ${ }^{17}$

\section{Linking with the EU}

Shortly after the scheme came into effect it was announced that it would be fully linked to the EU ETS by 1 July 2018. ${ }^{18}$ As an interim measure from 1 July 2015 (since presumably 2014) ${ }^{19}$ Australian entities would be able to use EU allowances to satisfy their obligations.

To facilitate linking the then Government announced that it would not proceed to implement a floor price as originally proposed. The decision to drop the price floor was controversial. ${ }^{20}$ First,

\footnotetext{
${ }^{12}$ But not of freely allocated units during the fixed price period, although these may be sold back to the Government.

${ }^{13}$ During the fixed price period up to a cap of $5 \%$ of the emissions obligations only.

${ }^{14}$ This initiative commenced in December 2011 and provides for credits to be issued on the basis of approved projects that reduce or avoid greenhouse gas emissions and/or increase carbon storage or sequestration: see http://www.daff.gov.au/climatechange/cfi (last visited 5 October 2012).

${ }^{15}$ For coal-powered electricity generators, only in the first four years and up to a cap and subject to passing certain criteria.

${ }^{16}$ Ranging from increased social security payments and family assistance to tax rate cuts and other tax reduction measures. Small businesses also received assistance in the form of accelerated tax deductions.

${ }^{17}$ In the case of fuel for heavy road transport the exemption applies only for the first two years.

${ }^{18}$ Department of Climate Change and Energy Efficiency media release, 28 August 2012 available at http://europa.eu/rapid/press-release_IP-12-916_en.htm\#PR_metaPressRelease_bottom (last visited 11 November 2012). Subsequently see: Clean Energy Legislation Amendment (International Emissions Trading and Other Measures) Act 2012 available at

http://www.aph.gov.au/Parliamentary_Business/Bills_Legislation/Bills_Search_Results/Result?bId=r4895

(last visited 21 April 2013).

${ }^{19}$ See footnote 4: with the proposal to move to a market pricing mechanism a year earlier it might be expected that EU credits could be utilized from the earlier date as well.
} 
price parameters provided some certainty for business planning. Secondly, there was a risk that the EU allowances would continue to price carbon much lower than the Australian Government forecasts. ${ }^{21}$ This would impact adversely on Australian Government revenue streams and the environmental objectives of the Australian regime.

The Government continued to propose a price ceiling, although it would be set by reference to the expected price of EU allowances. A price ceiling is a cost containment measure, providing some protection for Australian entities from an unanticipated spike in the carbon price. Notably the existence of such a measure is problematic to linkage. Linking schemes were one has a price ceiling and the other does not presents arbitrage opportunities and could undermine the environmental integrity of both schemes. ${ }^{22}$

Under the original Australian regime, Australian entities were to be able to use most Kyoto units. $^{23}$ Between 2015 and 2020 Australian emitters were to be able to source $50 \%$ of their required allowances from international sources (rising to 100\% from 2020). With the agreement to link with the EU regime a new sub-limit would apply to Kyoto units. Whilst entities would still be able to meet up to $50 \%$ of their liabilities through purchasing eligible international allowances, only $12.5 \%$ of their liabilities would be able to be met by Kyoto units. This made it more likely that Australian entities wishing to acquire international allowances would embrace the EU market. Furthermore, it provided some additional protection against the availability of "hot air" allowances asserting downwards pressure on the carbon price. ${ }^{24}$

\subsection{Japanese Developments - The TMG Scheme}

\section{Background - procrastination at the national level}

Pursuant to the Kyoto Protocol, Japan committed to reducing its emissions by 6\% relative to 1990 levels by 2012. A small scale voluntary ETS targeting small and medium sized businesses

\footnotetext{
${ }^{20}$ For example, see the Parliamentary debate for 10 October 2012 reported in Hansard at p 11932 available at http://www.comlaw.gov.au/Details/C2012B00173 (last visited 21 April 2013).

${ }^{21}$ At the time of writing the European market is pricing carbon at around AUD\$5 a tonne.

${ }^{22}$ Hitomi Kimura and Andreas Tuerk, Emerging Japanese emissions trading schemes and prospects for linking, Climate Strategies October 2008 (“Kimura and Tuerk 2008”) available at www.climatestrategies.org (last visited 5 November 2012).

${ }^{23}$ The Protocol established three market based mechanisms under which carbon permits might be effectively traded. Initially developed countries receive an assignment of units relative to their emissions "budget" (known as assigned amount units ("AAUs"). Developed countries are also granted removal units ("RMUs") in relation to domestic activities resulting in the net removal of greenhouse gases. RMUs and AAUs may be converted into emission reduction units ("ERUs"), the later through a "joint implementation project", namely a project that allows developed countries to work together by jointly implementing initiatives that reduce overall greenhouse gas emissions. Finally, there are certified emission reduction units ("CERS") generated from developed countries investing in projects that either reduce emissions or sequester carbon in sinks in developing countries, the so-called "clean development mechanism" designed to draw developing countries within the Protocol. The intention was that CERs and ERUs can be used by countries to comply with their emission limitation targets under the Protocol or by operators of installations covered by domestic ETSs in order to meet their carbon emission obligations or can be assigned to other countries. Under the Australian ETS it was proposed that the following international units might be used: most certified ERUs from CDMs, ERUs from JI projects and RMUs. Furthermore, the Government had stated that the types of international allowances recognized by both the EU and NZ ETSs and the restrictions on their use would be taken into account in determining which are acceptable to Australia.

${ }^{24}$ As to "hot air" see the discussion in Frank Jotzo and Regina Betz, "Australia's emissions trading scheme: opportunities and obstacles for linking” (2009) 9 Climate Policy 402.
} 
(“SMEs") was commenced in 2005. ${ }^{25}$ In 2008 this morphed into an experimental voluntary ETS that also encompassed a trial ETS based on a voluntary action plan established by the Keidanren ${ }^{26}$ and the verified emissions reduction scheme, a program allowing for credits to be generated through the reduction/removal of greenhouse gases employing sinks implemented pursuant to domestic projects. ${ }^{27}$ Although legislation directed at a 2013 start date was proposed, in response to sustained business resistance ${ }^{28}$ it was deferred. ${ }^{29}$ Then the triple disasters of 2011 made the introduction of a policy imposing further imposts on the economy inconceivable for the time being. ${ }^{30}$ The Government has even admitted that its 2010 United Nations climate change conference pledge to reduce emissions by $25 \%$ relative to 1990 by 2020 was no longer viable. ${ }^{31}$

It could be expected that the revival of any proposal to introduce a broad based ETS will continue to encounter industry resistance, especially from the powerful Keidanren business association. Furthermore, the difficulties presented by the Japanese political system of formulating and implementing policy involving multifaceted political issues, such as environmental reforms embracing fiscal measures, should not be underestimated. ${ }^{32}$

\footnotetext{
${ }^{25}$ Going by the acronym "JVETS", a regime based on the EU system. Unfortunately this scheme had only attracted a small number of participants. For participating firms, one third of the cost of new facilities to reduce emissions was borne by the Government. Firms were initially allocated emission allowances and set targets (absolute not intensity based). Those that failed to achieve their targets could purchase excess credits from firms that had exceeded their targets (or use j-CERS from Clean Development Mechanism projects) or return the subsidy to the Government: Stephanie Monjon, Implementation of an emission trading scheme in Japan: some food for thought, Climate Strategies October 2011 ("Monjon 2011") available at www.climatestrategies.org (last visited 5 November 2012). JVETS was apparently introduced as a voluntary scheme only, due to strong opposition from industry and the Ministry for the Economy, Trade and Industry. It was only of limited effectiveness as many major emitters did not join, targets did not require deep reductions and penalties were not severe: Hitomi and Tuerk 2008, supra.

${ }^{26}$ Operating since 1997 and based on the voluntary adoption of intensity targets.

${ }^{27}$ Going by the acronym "JVER". This regime is similar to the Australian carbon farming initiative allowing for the creation of credits through carbon sequestration activities. Note that a Bilateral Offset Credit Mechanism ("BOCM") is also being developed to enable Japanese entities to generate credits through emission reduction focused joint engagement with developing countries: see

http://www.iea.org/media/workshops/2012/ghg/3_TSUTSUMI_IEAIETAEPRI2012.pdf (last visited 30 October 2012). On the two trial schemes see J. Mochizuki, “Assessing the designs and effectiveness of Japan's emissions trading scheme” (2011) 11 Climate Policy 1337 - 1349 available at http://www.tandfonline.com/doi/abs/10.1080/14693062.2011.579289\#preview (last visited 13 November 2012).

${ }^{28}$ For example, see "Japan industry unites against carbon tax" (Dec 7, 2009) available at http://uk.reuters.com/article/2009/12/07/climate-japan-idUKTOE5B609U20091207 (last visited 5 November 2012).

${ }^{29}$ As to the experimental regime and the details of the December 2010 draft proposal see: Xianbing Liu, Kazunori Ogisu, Sunhee Suk and Kinichi Sudo, "GHG emissions trading schemes in Northeast Asia: an overview and analysis of current scenarios" in Larry Kreiser, Ana Yabar Sterling, Y Pedro Herrera, Janet E Milne and Hope Ashiabor (eds) Carbon pricing, growth and the environment, Abingdon Oxon Edwards Elgar Publishing 2012. Some of the political tradeoffs inherent in the design of the ETS are identified in Stephanie Monjon, Implementation of an emission trading scheme in Japan: some food for thought, Climate Strategies October 2011 available at www.climatestrategies.org (last visited 5 November 2012).

${ }^{30}$ On the ETS in Japan generally see the Ministry of the Environment website at http://www.env.go.jp/en/earth/ets/mkt_mech.html (last visited 13 November 2012).

${ }^{31}$ Leo Shanahan, “Japan's energy crisis puts ETS launch on ice” The Australian (February 29, 2012). The experimental ETS continues but solely on a voluntary basis with participating entities establishing their own emissions reduction targets although verification by the Government is a pre-requisite to any trading. Notably Japan is not supporting an extension to the Kyoto Protocol.

${ }^{32}$ Discussed in Liu Xianbing, Ogisu Kazunori, Suk Sunhee and Shishime Tomohiro, "Carbon tax policy progress in north-east Asia" in Larry Kreiser, Julsuchada Sirisom and Hope Ashiabor, Nov 01, 2011, Environmental Taxation in China and Asia-Pacific, Edward Elgar Publishing, Cheltenham, ISBN: 9780857937766 at p.116. In particular, the Ministries of Environment ("MOE”), Economy, Trade and Industry ("METI”), Land Infrastructure, Transport, Tourism ("MLIT"), Agriculture, Forestry and Fisheries ("MAFF") and Finance (“MOF”). Also see S. Rudolph and
} 
Japan also surprised many observers by its withdrawal from the Kyoto Protocol at the end of the first commitment period. ${ }^{33}$ With this withdrawal and a change of Government in 2012 the country's climate change policy, including its emissions reductions commitment, has been reoriented away from domestic reductions to providing emissions reduction technology to developing nations. ${ }^{34}$

\section{The TMG regime 35}

Against this background of procrastination at the national level, cap and trade ETSs have operated in Tokyo and Saitama ${ }^{36}$ since 1 April 2010 and 2011 respectively. Although subnational schemes, they are not insignificant. For example, Tokyo's greenhouse gas emissions totaled 59.6 million tonnes in 2006 putting it on par with countries such as Denmark and Norway. ${ }^{37}$

In the first two years of operation of the TMG regime emissions reductions of $23 \%$ have been reported ${ }^{38}$ suggesting that it has been highly successful. The features of the regime can be outlined as follows: ${ }^{39}$

- The scheme is mandatory and covers approximately 1,400 commercial and public facilities that have a total consumption of fuels, heating and electricity of at least 1,500 kilolitres per year (crude oil equivalent applying a conversion factor to other energy sources consumed). It is, thus, a downstream scheme focusing on indirect emissions and covers around $20 \%$ of total carbon dioxide emissions in Tokyo. ${ }^{40}$

- Whilst the scheme only applies to energy related carbon dioxide emissions if a track record of total emissions reductions for greenhouse gases other than energy related

S. J. Park, "Lost in Translation? The political economy of market-based climate policy in Japan” in C. Dias Soares et al (ed), Critical Issues in Environmental Taxation Volume VIII, Oxford University Press, Oxford $2010,163$.

33 The rationale for Japan's decision is discussed in Andrew Light, "Has Japan killed the Kyoto Protocol?” Center for American Progress website article dated 8 December 2010 available at http://www.americanprogress.org/issues/green/news/2010/12/08/8733/has-japan-killed-the-kyoto-protocol/ (last visited 11 March 2013).

${ }^{34}$ See Justin Dabner and Satoshi Kurokawa, “Japan’s new direction on climate change” East Asia Forum (3 July 2013) available at http://www.eastasiaforum.org/2013/07/03/japans-new-direction-on-climate-change/ (last visited 22 August 2013).

${ }^{35}$ Generally see Stefan Niederhafner, “The governance modes of the Tokyo Metropolitan Government Emissions Trading System” (2013) available at http://hdl.handle.net/10086/26005 (Niederhafner 2013).

36 The Saitama regime substantially replicates the Tokyo regime but is a voluntary arrangement (in the sense that there are no sanctions for non-compliance) that applies to around 600 entities. Allowances are provided and these may be traded. Again offsets are available. Agreement was reached to link the two regimes in September 2010: Monjon 2011, supra.

${ }^{37}$ Tokyo cap-and-trade program: Japan's first mandatory emissions trading scheme, March 2010, Bureau of the Environment, Tokyo Metropolitan Government ("BOE 2010”).

${ }^{38}$ The Tokyo cap-and-trade program achieved 23\% reduction in the $2^{\text {nd }}$ year, TMG media release, 21 January 2013.

39 See The Tokyo Metropolitan Environmental Security Ordinance “Tokyo cap-and-trade program” for large facilities <Detailed Documents>, Bureau of Environment, TMG, 30 March 2012 available at www.kankyo.metro.tokyo.jp/en/climate/ (last visited 7 April 2013).

40 Sven Rudolph and Takeshi Kawakatsu, Tokyo's greenhouse gas emissions trading scheme: a model for sustainable megacity carbon markets?, Joint Discussion Paper Series in Economics No 25-2012 ("Rudolph 2012 ") available at http://www.uni-marburg.de/fb02/makro/forschung/magkspapers/25-2012_rudolph.pdf (last visited 4 March 2013). 
carbon dioxide can be independently verified such entities may be permitted to use these reductions to fulfill their carbon dioxide reduction obligations. ${ }^{41}$ Notably $95 \%$ of Tokyo's emissions are carbon dioxide energy based emissions. ${ }^{42}$

- Entities affected must reduce their carbon dioxide emissions based on (absolute) caps or cover any excess emissions by purchasing emissions allowances from other entities covered by the scheme.

- Alternatively, entities may satisfy their obligations by acquiring offset credits from four other sources. More particularly, renewable energy certificates granted to suppliers generating electricity through renewable resources may be acquired and relied on, ${ }^{43} \mathrm{SME}$ facilities within the Tokyo area (ie too small to be covered by the ETS) that implement energy saving measures resulting in verifiable emission reductions can be issued with credits which may be acquired by liable entities, ${ }^{44}$ and from 2015 limited credits ${ }^{45}$ will also be available in relation to verified emissions reductions by large entities outside the TMG program. ${ }^{46}$ Credits issued under Saitama's regime may also be relied on. Saitama credits may include both those acquired from entities to which its ETS applies and from SMEs that have implemented energy saving measures resulting in verified emissions reductions.

- Five year commitment periods are mandated. Under the 2010 to 2014 period the cap is set at a 6 or $8 \%$ reduction in the base year emissions ${ }^{47}$ with a second commitment period reduction set at $17 \%$. Whilst this would seem to reflect a relatively stringent requirement, such that TMG expects allowance prices to increase to up to US\$150 per tonne in the second period, ${ }^{48}$ in fact due to both the economic downturn and, possibly, the effect of

${ }^{41}$ Whilst these reductions cannot directly give rise to tradable credits the counting of such reductions may result in excess reductions that can otherwise be converted to tradable credits. This measure is expected to only apply to a handful of facilities known to the TMG: Meeting with TMG officials, 5 April 2013.

${ }^{42}$ Kyle DuPont (Padeco Co Ltd), Cities and climate change mitigation: case study on Tokyo's emissions trading system, World Bank May 2010 (“DuPont 2010”) available at http://siteresources.worldbank.org/INTURBANDEVELOPMENT/Resources/3363871226422021646/Tokyo_ETS_Padeco.pdf (last visited 4 March 2013) and see http://siteresources.worldbank.org/INTURBANDEVELOPMENT/Resources/3363871226422021646/Directions5.pdf?resourceurlname=Directions5.pdf (last visited 4 March 2013).

${ }^{43}$ See DuPont 2010 at page 2-9 for discussion of the green electricity certification (and also the city solar energy bank) initiatives that may give rise to these credits.

${ }^{44}$ BOE 2010 at paragraph 3.4.1.

${ }^{45}$ These may only be used to satisfy one third of a facility's reduction obligations.

${ }^{46}$ Registration is required along with adherence to monitoring, reporting and verification rules. Credits up to one third of a company's obligations only may be relied upon.

${ }^{47} 6 \%$ for factories and most buildings, otherwise 8\% for buildings and facilities in which air conditioning and heating from district cooling and heating plants make up $20 \%$ or less of energy consumption. Base year emissions are calculated as the average of any three consecutive years between FY2002 and FY2007. Updating of the permitted emissions is available upon a change in floor space, purpose of use or amount of equipment used. There is also scope to ameliorate this reduction level for the following fiscal year period (by $1 / 2$ or $1 / 4$ ) if certification as having made outstanding or excellent progress with regards to the implementation of measures against global warming is obtained and this can be maintained. One rationale for this measure is to accommodate (mainly) new businesses that had already achieved substantial emissions reductions and might find it difficult to achieve further significant reductions from the base year amounts.

${ }^{48}$ Rudolph 2012 at section 3.1. 
energy rationing following the Fukushima incident, the first commitment period caps have already been met in the first two years. ${ }^{49}$

- Allowances are allocated free of charge according to the grandfathering method based on the base year emissions adjusted for the 6 or $8 \%$ reduction. A reserve of allowances is maintained to be issued to new entrants based on their average actual emissions over two to three years. ${ }^{50}$ Where emissions levels fall below 1,000 kilolitres for the previous year or 1,500 kilolitres for three consecutive years the facility may leave the program.

- Emissions reports lodged with TMG are to be verified by a registered third party verification agency. The calculation of emissions is based on the consumption of gas and electricity converted to carbon dioxide equivalent emissions measured in metric tonnes using an emissions factor. This factor is fixed irrespective of changes in the way in which electricity is generated and thus has not been adjusted for an increase in coal fired electricity generation with the shutdown of nuclear power stations. ${ }^{51}$ Overall though, the monitoring, reporting and verification procedures are thorough. ${ }^{52}$

- Penalties are imposed in the event of a breach of the emissions cap. At first instance the entity will be ordered to acquire credits (or make reductions) equal to 1.3 times the shortfall. If this order is not complied with then punishment can include fines of up to Y500,000 (payment of which does not absolve the breach), publication of the breach and payment of compensation to TMG for purchasing allowances on behalf of the noncompliant entity. Other penalties apply, for example for failing to lodge a report. ${ }^{53}$ The penalty system is considered stringent. ${ }^{54}$

- Each facility has an account with the Registry of Reductions. A record needs to be made when acquiring, transferring or using excess reduction or offset credits to fulfill obligations. Only excess credits beyond the annual reduction obligations may be traded once the reductions have been verified and converted into credits in a trading account upon application. ${ }^{55}$ Excess credits up to half of the entity's base year emissions calculation may be sold. TMG has no part in the sales process other than to provide a website for participants to engage via and the holding of annual "matching” seminars. It

\footnotetext{
${ }^{49} 93 \%$ of covered facilities have already reduced their emissions by in excess of the required first commitment period amount by the end of the second year with $70 \%$ having also achieved their likely second commitment period reductions of 17\%: The Tokyo cap-and-trade program achieved $23 \%$ reduction in the $2^{\text {nd }}$ year, TMG media release, 21 January 2013.

${ }^{50}$ With the execution of specified energy saving measures assumed, thereby denying new entrants the opportunity to inflate their allowance.

${ }^{51}$ Although it may be for the second compliance period: Meeting with TMG officials, 5 April 2013.

${ }^{52}$ Rudolph 2012 at section 2.2.

${ }^{53}$ Generally see http://www.kankyo.metro.tokyo.jp/kouhou/english/index.html (last visited 13 November 2012).

${ }^{54}$ Rudolph 2012 at section 3.1.

${ }^{55}$ In contrast to the EU regime that allows for trading prior to verification. The rationale for the TMG procedure is to encourage facilities to rely primarily on reduction strategies rather than trading: DuPont 2010 at appendix 2. In the year following the end of the five year commitment period credits will automatically be entered into the trading account once excess reductions are verified by TMG.
} 
has been suggested that the trading mechanism results in high transaction costs and hampers the efficiency of the market. ${ }^{56}$

- As with the commitment period, the compliance period is also five years. Whilst an emissions report must be lodged by the end of November each year, and any reductions exceeding the annual obligations may be traded once verified by TMG, any deficiencies do not need to be made up (through purchases of credits) until the end of the five year commitment period. In lieu of selling credits arising from excess reductions at the end of the first commitment period they may be banked and used in the second commitment period ${ }^{57}$ but borrowing for the purposes of trading is not allowed.

- TMG reserves the power to implement certain measures to intervene in the market to contain the cost of allowances. In particular, the supply of allowances may be increased by expanding the supply of offset credits, for example from reduction activities by SMEs or, as a further measure, increasing the use of credits from outside Tokyo or enabling the use of Kyoto credits (which otherwise are not accepted). It is not expected that this measure would be utilized except in extreme circumstances and following consultation. ${ }^{58}$

\subsection{Comparing the Australian and TMG regimes}

All ETSs involve a trade off between environmental effectiveness and cost containment. How this trade off is struck determines the features of the regime and its level of ambition. Additionally both institutional and constitutional considerations can impact on ETS design.

A comparison of some of the main features of the two regimes is attempted in the table below followed by an analysis of some of the differences. For these purposes it is assumed that the proposals of the former Australian Government are honoured.

\footnotetext{
${ }^{56}$ Ibid. Rudolph identifies that no market has yet been established with the reluctance to trade demonstrated by the fact that only 200 facilities (17\%) had so far opened an account which would enable them to acquire tradable credits. See DuPont 2010 for a description as to how the market operates (at page 2-9).

${ }^{57}$ Replication for the second and third commitment periods is not currently anticipated: Meeting with TMG officials, 5 April 2013.

${ }^{58}$ Meeting with TMG officials, 5 April 2013.
} 
Table 1 - Comparison of the design features of the Australian and TMG ETSs

\section{Design Feature}

\begin{tabular}{|c|c|c|}
\hline Type of target & Absolute & Absolute \\
\hline Ex-post adjustment & Not proposed. & No \\
\hline $\begin{array}{l}\text { Price cap and/or market intervention } \\
\text { (cost containment) measures }\end{array}$ & $\begin{array}{l}\text { Price cap at AUD } \$ 20 \text { above expected EU } \\
\text { carbon price for } 2014 / 15 \text { until } 2018 \text {. No other } \\
\text { intervention measures. }\end{array}$ & $\begin{array}{l}\text { Emergency measures to sell additional } \\
\text { allowances. }\end{array}$ \\
\hline Borrowing & Up to $5 \%$. & Prohibited \\
\hline Continuance & Ongoing & Ongoing (confirmed thru to 2019 at this stage) \\
\hline Banking & Unlimited & Limited to use in commitment period two. \\
\hline Commitment periods & Annual - specified five years in advance. & Five years. \\
\hline Target stringency & $\begin{array}{l}\text { To be specified from } 2014 \text {. Currently trade } \\
\text { exposed industries receive substantial } \\
\text { concessions in the form of free units. }\end{array}$ & $\begin{array}{l}\text { 6-8\% in the first commitment period. } 17 \% \text { for } \\
\text { second period (2015 - 2019). Concessions } \\
\text { available for entities implementing exceptional } \\
\text { measures. }\end{array}$ \\
\hline Limits on foreign allowances & $\begin{array}{l}50 \% \text { foreign (100\% from } 2020) 12.5 \% \text { Kyoto } \\
\text { units sub-limit. }\end{array}$ & No foreign allowances recognized. \\
\hline Other domestic offsets/credits & Carbon farming initiative & $\begin{array}{l}\text { Renewable energy credits, Tokyo SME } \\
\text { reduction credits, outside Tokyo large entity } \\
\text { reduction credits (from } 1 \text { April 2015), Saitama } \\
\text { credits. }\end{array}$ \\
\hline $\begin{array}{l}\text { Level of compulsion, governance and } \\
\text { enforcement }\end{array}$ & Mandatory (Clean Energy Regulator (“CER”)) & $\begin{array}{l}\text { Mandatory (Bureau of the Environment } \\
\text { (“BOE”)) }\end{array}$ \\
\hline
\end{tabular}




\begin{tabular}{|c|c|c|}
\hline Compliance (trading) period & Annual (1 July - 30 June) & Annual (1 April - 31 March) \\
\hline Monitoring, verification and reporting & $\begin{array}{l}\text { Reports of large emitters (125,000 tonnes p.a.) } \\
\text { must be audited. Other audits by the CER } \\
\text { possible. }\end{array}$ & $\begin{array}{l}\text { Detailed reporting rules, independent } \\
\text { registered verification agencies and competent } \\
\text { BOE supervision. }\end{array}$ \\
\hline Sanctions for shortfalls & $200 \%$ of the average price of units for the year. & $\begin{array}{l}\text { Credits equal to } 1.3 \text { times the shortfall to be } \\
\text { acquired, fine up to } ¥ 500,000 \text { and naming. }\end{array}$ \\
\hline Leakage control & Trade exposed industries receive concessions. & None \\
\hline Level of application & Upstream bias (large emitters) & Downstream bias (large energy consumers) \\
\hline Sector and gas coverage & $\begin{array}{l}\text { Large emitters in most sectors nationwide. } \\
\text { Four types of gases covered ( } 60 \% \text { of } \\
\text { Australia's greenhouse gas emissions). }\end{array}$ & $\begin{array}{l}\text { Large consumers of fuels, heating and } \\
\text { electricity in the TMG area. Primary focus on } \\
\mathrm{CO}_{2}\left(20 \% \text { of Tokyo's } \mathrm{CO}_{2} \text { emissions }\right) \text {. }\end{array}$ \\
\hline Allocation of allowances & Auction (some free allocations) & Grandfathering (with limited updating) \\
\hline New entrants and business closure & General structure accommodates most issues. & Detailed rules. \\
\hline Registries and trading mechanism & $\begin{array}{l}\text { Online registry maintained by the CER. Units } \\
\text { tradeable by account holders once acquired. } \\
\text { Auctions by the CER expected to set price } \\
\text { signal. Units measured in per tonne of } \mathrm{CO}_{2} \text {. }\end{array}$ & $\begin{array}{l}\text { Online registry maintained by TMG. } \\
\text { Tradeable allowances on application following } \\
\text { TMG verification of emissions reductions. } \\
\text { Website and matching seminars to facilitate } \\
\text { trade. Allowances up to half base year } \\
\text { emissions may be traded. Allowances } \\
\text { measured in per tonne of } \mathrm{CO}_{2} \text {. }\end{array}$ \\
\hline $\begin{array}{l}\text { Kyoto Protocol (allowances shadowed by } \\
\text { Kyoto units - ie. convertible to ERUs) }\end{array}$ & Unspecified. & No \\
\hline Existing linkage partners & Full linkage with EU proposed 1 July 2018. & Saitama \\
\hline
\end{tabular}


Absolute targets and ex-post adjustments

An ETS may mandate that entities not exceed targets expressed as emissions per unit of output or activity or even per unit of input. These are known as intensity or relative targets. One limitation of such targets is that emissions may continue to increase as a result of increases in activity. They are thus more liberal than absolute targets which are set by reference to the historical emissions ("grandfathering") with a reduction factor applied or "benchmarking".

Emissions limits are specified over a period usually described as the "commitment period" and are typically established at the start of that period. However some regimes allow for subsequent adjustments as a price controlling measure. Such a measure could enable politically-motivated market influence and undermine the market. ${ }^{59}$

The absolute nature of the targets of both regimes and the lack of any ex-post adjustment mechanism enhances their environmental integrity.

\section{Price cap and cost containment measures}

Unsurprisingly both regimes contain cost containment measures. In the case of TMG the right to adopt emergency measures is reserved should the price rise too high. In Australia's case a price ceiling is mandated through to 2018.

At the same time TMG is also concerned with the price of allowances being too low. ${ }^{60}$ Notably the policy behind the TMG regime is predicated on a much higher price than both the current EU and Australian prices. However the ease with which the TMG caps have been met has meant that few trades have occurred ${ }^{61}$ and, with the large stock of excess reductions, downwards pressure on the price in the future could be expected notwithstanding the original policy intent and inefficiencies in the market framework. TMG might respond to this by intervening in the market to buy up or cancel allowances. Such a power is inconceivable under the Australian model with the repeal of the price floor mechanism following the agreement to link with the EU.

\footnotetext{
${ }^{59}$ Mace 2008 at paragraph 3.4.4.

${ }^{60}$ An influx of low priced allowances is feared: see Rudolph 2012 citing interviews with BOE officials.

${ }^{61}$ Such information is secret (unless voluntarily declared by market participants) although there is report of one trade at US\$142 per tonne: Rudolph 2012 at section 3.2. TMG records reveal that while no trades in excess allowances occurred during FY2011 (the first year of possible trading) one occurred in FY2012 (as at 28/2/13) with a further eight trades in other forms of credits. Nine entities did convert excess reductions into tradable credits: apparently most entities have banked their excess allowances awaiting clarification as to commitment period two reduction obligations. Two attempts to auction credits by the TMG met with limited success - there were no expressions of interest on the first advertised occasion and only one sale on the subsequent occasion (at Y10,000 per tonne). Whilst the price at which private trades occurs is not publicly available the TMG auctions are meant to provide a price signal - preferred at between Y8,000 to Y10,000 (US\$80 to \$100) per tonne - based on survey information and an annual "matching" seminar. Furthermore, it is anticipated that the involvement of market place intermediaries will assist in establishing a market price. Notably no trades between Saitama and Tokyo based entities have occurred as at April 2013: Meeting with TMG officials 5 April 2013.
} 


\section{Borrowing}

The Australian intention to allow limited borrowing also differs from the TMG model. The opportunity for entities to borrow allowances from future periods asserts downwards pressure on the carbon price and can encourage entities to lobby for a relaxation of future targets and poses the risk that such entities may terminate their activities after having utilized their future allowances. However the tightness of the Australian limit on borrowing would minimise the downwards impact on price. Notably the Australian approach is stricter than the EU rules. ${ }^{62}$

\section{Banking}

Both regimes have liberal rules as to banking, namely the ability to use excess allowances in one period to meet obligations of future periods. However the TMG regime requires banked allowances from the first commitment period to be utilised in the second commitment period. It is understood that it is not proposed that the banking option be extended into the third commitment period. Notably, banking does not harm a scheme's environmental credentials where it reflects mitigation methods or excess purchases over needs (rather than over-allocation of free allowances).

\section{Commitment and compliance periods}

TMG creates five year periods whereas the Australian regime requires reconciliation between emissions and allowances annually with the required emissions caps specified for each year five years in advance. The rationale for the longer Tokyo compliance period is said to be to facilitate companies meeting caps via longer term investments in energy conservation. ${ }^{63}$ Given the Australian rules permitting banking and, especially, (limited) borrowing and the expected fluid market with trades possible from the commencement of the period this difference may be only cosmetic.

\section{Target stringency}

The TMG first commitment period caps (set at a $6 \%$ or $8 \%$ emissions reduction) appeared reasonably stringent at the outset of the regime but in the event they have been easily achieved. The second commitment reductions from 2015 have been foreshadowed as 17\%. The Australian caps for when it was proposed to move to a full ETS have never been specified. It is understood that a uniform reduction obligation is envisaged (subject to specific industry concessions) whereas under the TMG ETS the 6\% or 8\% reduction factor in the first compliance period depends on the entity's industry categorisation.

\footnotetext{
${ }^{62}$ A comparison of borrowing rules can be found at http://www.emissions-euets.com/borrowing (last visited 7 March 2013).

${ }^{63}$ IETA Tokyo at 6.
} 
It should be observed that it is not so much the level of the emissions target in each jurisdiction that sets the level of stringency but rather the relative shortage of emissions allowances that is created and hence the extent of the incentive to reduce emissions.

\section{The recognition of allowances from other schemes and jurisdictions}

Each ETS allows for offsets generated under certain domestic regimes. Furthermore, the Australian ETS allows for the limited used of Kyoto units and EU allowances whilst the TMG regime recognises allowances generated under the Saitama ETS. ${ }^{64}$ Recognition of foreign allowances exerts downwards pressure on the carbon price, raises integrity concerns and (effectively) exports emission reduction activities resulting in less domestic reductions. The later is not necessarily an issue given the global nature of emissions. Where remissions are reduced does not matter from an environmental perspective. If the relative cost of abatement is less in one jurisdiction then focusing on reductions there first makes greater economic sense.

The integrity of these external allowances is critical though. Jurisdictions need to be confident that they do, in fact, represent a real reduction in emissions.

The lack of sanctions supporting compliance with the Saitama regime rendering it, effectively, voluntary could have a downwards influence on the carbon price in Tokyo. A similar downwards influence on the carbon price could be expected in Australia from recognising units from the large (currently over supplied) EU market.

Notably, whilst the carbon price is around US $\$ 140$ per tonne in Tokyo ${ }^{65}$ it is currently nearer US $\$ 5$ and US\$25 per tonne in the EU and Australia respectively. The price in Tokyo is clearly very high in relative terms this being possibly attributable to the trading mechanism engendering a lack of market liquidity and the already high Japanese energy efficiency so rendering further reductions more expensive. ${ }^{66}$ Nevertheless TMG is reluctant to recognise foreign allowances concerned that the availability of cheap foreign credits would drive down the price in Tokyo and lead to a reduced incentive to abate and less domestic reductions.

This concern arises from taking a domestic rather than global perspective. Nevertheless, the concern might be ameliorated by placing limits on the amount of foreign credits that may be utilised with this limit reviewed on an ongoing basis. ${ }^{67}$ There are, in fact, precedents for this in the restriction placed by TMG on the proposed use of outside Tokyo credits and also by Australia on the use of Kyoto and other foreign credits. A similar restriction might achieve a

\footnotetext{
${ }^{64}$ There is mutual recognition as TMG allowances may be relied on by Saitama based entities.

${ }^{65}$ The first trades occurred in August 2010 at \$142US per tonne: IETA Tokyo at 5.

${ }^{66}$ Ibid.

${ }^{67}$ An additional "fix" that might serve to partially offset the loss of abatement incentive arising from a price reduction would be to auction allowances rather than embrace free allocation.
} 
compromise between the pursuit of domestic policy considerations whilst also allowing TMG to be part of a global network.

There is a further reason why TMG might consider greater recognition of foreign allowances with some convergence of the carbon price. Tokyo based entities with an international clientele or competitors may suffer a competitive disadvantage if they face a carbon price far in excess of that experienced globally. The city is already branded as one of the most expensive in the World $^{68}$ and any additional cost differential imposed on Tokyo based businesses will detract from its World financial centre prospects and renewed export endeavours. Carbon leakage is also conceivable, as discussed below.

\section{Level of compulsion, governance and enforcement}

Both regimes are mandatory with the TMG ETS subject to stringent monitoring, reporting and verification rules enforced by TMG officials at the Bureau of the Environment with the assistance of third party verifiers. Similarly, the Australian system established a regulator to attend to supervision and enforcement with the aid of independent auditors. The proposal is for the Australian rules to be based on international standards. Notably reports of especially large emitters would be audited before lodgement and the regulator had indicated that audits of other entities would be undertaken in specified circumstances.

\section{Sanctions for shortfalls}

The penalty regimes differ for each regime but both appear similarly stringent. Although the Australian penalty absolves entities from their obligations the penalty is set at twice the current market price thus preventing the penalty from acting as a de facto price cap. Similarly, the first level TMG penalty for excess emissions is a requirement to purchase 1.3 times the amount of allowances that would otherwise have been required (so again the penalty does not operate as a de facto price cap).

\section{Leakage control}

It is conceivable that facilities operating within the jurisdiction of TMG might relocate, effecting carbon leakage, a term coined to refer to the phenomenon where origin based carbon pricing leads to a reorientation of carbon emitting activities away from jurisdictions that price carbon to destinations that do not. In the absence of similar regimes operating throughout Japan the only way this possibility might be mitigated would be for TMG to provide some concessions for types of facilities most able or likely to relocate. This does not seem practical though and might raise equity considerations.

\footnotetext{
${ }^{68}$ Erica Ho, “And the World's 10 most expensive cities of 2013 are” Time Newsfeed (6 February 2013) available at http://newsfeed.time.com/2013/02/06/and-the-worlds-10-most-expensive-cities-of-2013-are// (last visited 7 April 2013).
} 
In contrast, Australia had provided trade exposed industries with concessions in order to minimise the chances of relocation and ensure that they remain internationally competitive. Many of these concessions were foreshadowed to expire or be pared back with the establishment of the full trading scheme subject to the responses in other jurisdictions, particularly potential linkage partners such as the EU and NZ. ${ }^{69}$

\section{Level of application and coverage}

The designers of an ETS must decide upon whom to impose the requirement to account for emissions through the purchase of allowances. There is a spectrum of possibilities from imposition on producers and importers of fuels, to those using the fuels to create energy and emitting greenhouse gases (primarily the energy suppliers and some manufacturers - making direct emissions accountable) through to where the ultimate consumer of a product or service may have to account for the indirect emissions embedded in the item or service (distinguished as upstream or downstream approaches). ${ }^{70}$ From a theoretical perspective the incentive effect away from emissions intensive activities should be the same as under either approach the ultimate consumer would be paying for the price on carbon, in the upstream approach the carbon price is reflected in the price of the fuel, energy, item or service. However the potentially wider coverage and administrative and compliance cost advantages of an upstream approach render it more attractive.

The TMG regime operates further downstream in contrast to the Australian regime being more upstream in character directed at, fundamentally, energy creators. The downstream focus of the TMG regime, on large consumers of energy, results in its coverage extending primarily to commercial buildings, in particular, office towers. ${ }^{71} \mathrm{~A}$ rationale for this downstream is that whilst around $40 \%$ of the energy consumed in Tokyo is electricity, $90 \%$ of that electricity is generated outside the jurisdiction of the TMG.

Thus, in addition to being a more upstream regime, the Australian regime has a broader sectoral coverage than the TMG regime. Not only does it apply to energy generation facilities but also many industries such as aluminium production, steel manufacturing, pulp and paper manufacturing, glass making, cement production and petroleum refining are within its net. Furthermore, whilst the primary focus is on carbon dioxide emissions, four greenhouse gases in total are caught. ${ }^{72}$

\footnotetext{
${ }^{69}$ See the discussion at http://www.aph.gov.au/Parliamentary_Business/Bills_Legislation/bd/bd1112a/12bd068 (last visited 8 March 2013).

${ }^{70}$ The OECD 2002 report describes an approach that caps emissions at the emissions level as "direct" and one where the ultimate consumers are held accountable for the emissions embedded in the goods or services they consume as "indirect": see paragraph 3.3.

${ }^{71}$ Around $80 \%$ buildings and the balance factories: BOE 2010 at page 11.

${ }^{72}$ The others are methane, nitrous oxide and perfluorocarbon from aluminum smelting.
} 


\section{Allocation of allowances}

Essentially two methods can be adopted to allocate allowances. A government might sell them through a competitive auctioning process or allowances could be allocated free of charge in proportion to the entity's past emissions (grandfathering). In the case of grandfathering an optional feature is for each entity's allocation proportion of the total allowances to be adjusted up or down in the next period on the basis of an increase or decrease in its activity level (updating).

The allocation method needs to be such as to not affect the legitimacy of the system as a whole. The possibility of windfall profits to market participants is a risk with free (over) allocation. In the case of an auctioning system care must be taken to ensure that the auctions operate with market efficiency and integrity in mind. In particular, competitive or collusive conduct by bidders at an auction must be avoided. ${ }^{73}$ Auctioning in one jurisdiction where the allowances are freely allocated in another can lead to competitive distortions between competing enterprises.

The TMG regime adopts the grandfathering method of allocating allowances in contrast to the Australian auctioning proposal. Although some competitiveness issues could arise, in reality, limited direct competition is likely between the entities affected in each jurisdiction. ${ }^{74}$

\section{New entrants and business closure}

The TMG regime has developed detailed rules for the treatment of new entrants and business closure. There is less necessity for specific rules in Australia as the general structure of the regime would accommodate most issues relating to new entrants and business closure. ${ }^{75}$

\section{Registries and trading mechanism}

Both TMG and Australian allowances are expressed in metric tonnes of carbon dioxide although various conversion factors are used in each jurisdiction. The TMG system (relying on a website to provide for bilateral trades of allowances first certified by TMG as excess) results in high transactions costs and inefficiencies and may warrant revision. The Australian system provides for registration and online trading.

\section{Kyoto units}

Jurisdictions that remain parties to the Kyoto Protocol may wish to ensure that any allowances acquired from a foreign source are backed by Kyoto units, which can then count towards the country's international emissions reduction obligations, and that their allowances are similarly

\footnotetext{
${ }^{73}$ Mace 2008 at paragraph 3.7.1. Also see M. J. Mace and J. Anderson, "Transnational aspects of a linked carbon market”, (2008) 2 Carbon and Climate Review 190.

${ }^{74}$ There may be some potential for competition, for example between Australian steel mills and those operating in the TMG area. However, as discussed, most trade exposed Australian industries are being provided with some protection under the ETS arrangements.

${ }^{75}$ The structure of the TMG regime (especially free allocation and coverage dependent on consumption of energy not level of emissions) mandates the need for complex "new entrants" and "business slow down / closure" rules.
} 
backed. ${ }^{76}$ The Australian regime does not specify whether its allowances would be shadowed by Kyoto units although this would be an expected measure. Although there is no foreign dimension to the TMG regime it would not be clear, in any event, how a sub-national entity, such as TMG, could generate a transfer of Japanese Kyoto units. ${ }^{77}$

\section{Linkage partners}

The Kyoto Protocol envisages that the various national and sub-national ETSs would be linked to form a global market for carbon. This would allow global emissions to be reduced in the most cost effective manner with those jurisdictions where the marginal cost of abatement is lowest most likely to generate excess credits for sale globally. As emissions know no jurisdictional boundaries ultimately it does not matter where the abatement occurs, just that it occurs.

Linkage, though, involves considerable integrity and administrative issues. Furthermore, the level of ambition reflected in the compromise between environmental objectives and cost containment in each jurisdiction's ETS is likely to vary. Linkage will have the effect of settling all linked regimes at, or towards, the level of the regime with the weakest environmental objectives as that jurisdiction's regime will exert downwards pressure on the carbon price.

Importantly, whilst the detail of a regime's features may render it more or less compatible with another regime few, if any, features will deny the ability to link as legal "workarounds" are typically available. ${ }^{78}$ Political acceptability and, indeed, political will are much more significant to the decision whether two regimes might link especially as with linkage comes a (partial) loss of control by each government over its domestic ETS and the potential to "import" market imperfections. ${ }^{79}$

Notably Tokyo has linked with Saitama which jurisdiction has implemented a similar, although voluntary regime. Australia has proposed a link with the EU. This was a significant decision given the collapse in the carbon price in the EU and the differences in the relative sizes of the markets with the expected result that the EU market will dominate and Australia will be a price taker. The resultant downwards pressure on the price would be ameliorated by the proposed $50 \%$

\footnotetext{
${ }^{76}$ Linking to or between systems outside the Kyoto Protocol is feasible although not contributing to a negotiation of a global burden sharing regime: see Andreas Tuerk, Michael Mehling, Christian Flachsland, Wolfgang Sterk, "Linking carbon markets: concepts, case studies and pathways", (2009) 9 Climate Policy 341 - 357 at 344 - 345 ("Tuerk at al (2009)").

${ }^{77}$ Note that Japan has withdrawn from the second commitment period of the Kyoto Protocol.

${ }^{78}$ It has been suggested that the Australian regime is designed to be readily linked to other ETSs: "Australia. The World's carbon markets: a case study guide to emissions trading” Environmental Defense Fund, International Emissions Trading Association, June 2013 at 8 available at http://www.ieta.org/assets/Reports/EmissionsTradingAroundTheWorld/edf_ieta_australia_case_study_september_2 013.pdf (last visited 5 March 2014).

${ }^{79}$ Generally see Christian Flachsland, Robert Marschinski and Ottmar Edenhofer, "To link or not to link: benefits and disadvantages of linking cap-and-trade systems” (2009) 9 Climate Policy 358. The authors generate a useful table (Table 2) summarizing the potential advantages and disadvantages of linking.
} 
limit on the use of international permits although the removal of the proposed price floor was a significant concession to the Europeans. It is suspected that the then Labor Government, facing an election, hastened forward this decision to lock Australia into an international framework in the hope that this would make repeal of the regime less viable if it lost government. Furthermore, the Government hoped that the forecast fall in the carbon price would resonate with the community concerned at the relative discrepancy in the price between Australia and the EU during the Australian regime’s fixed price period.

\subsection{Philosophical differences between the regimes}

It might be suggested that the Australian and TMG regimes have a fundamental philosophical difference. The Australian regime is premised on harnessing market forces to bring about emissions reductions, from the initial allocation of allowances via auction through to the unfettered right to immediately trade in these allowances. An entity's right to emit carbon dioxide is then based on the allowances it holds at the due date for surrender. In contrast, the TMG regime has greater regulatory involvement and might be more aptly described as a reductions (not allowances) system. Reduction targets are specified and only if these are met to the satisfaction of TMG may any excess reductions then be converted to allowances which can be traded.

Essentially though, apart from timing issues as to when credits are available for trading (upon the initial allocation or acquisition in Australia; only upon application once excess reductions for an annual compliance period are verified in Tokyo) both systems are focused on generating a financial incentive to reduce emissions. The "asset" that a TMG entity with verified excess reductions acquires may be disposed of to another entity, providing the recipient with a right to greater emissions. In this sense both regimes provide for trading in emissions allowances, only the TMG regime is post the event in the sense that an entity must already have a verifiable excess in emissions reductions rather than a mere expectation that it has excess allowances that it can trade. $^{80}$

It is understood that TMG's ETS has been carefully crafted to avoid creating property rights that might otherwise raise the prospect that the TMG has exceeded its constitutional powers. Article 29(2) of the Japanese Constitution can be interpreted as stating that "Property rights shall be defined by law, in conformity with the public welfare." Even though the word "law" is used in the English version of the Constitution, the word houritsu is used in the original Japanese text. An interpretation of houritsu is a statute formally legislated by the national government. On this interpretation only the national government is able to make property rights and a local

\footnotetext{
${ }^{80}$ It has, therefore, been suggested elsewhere by the author that any philosophical differences should not amount to a barrier to linking the two regimes although it is conceded that the requirement for TMG to verify reductions prior to a tradable asset emerging and the subsequent mechanism for trading may hinder trades across a linked market: Justin Dabner, "Linking the Australian and TMG emissions trading schemes” unpublished paper.
} 
government like TMG has no such power. In order to avoid this obstacle, TMG did not introduce emission allowances, which could be deemed as a kind of property right. Instead, as noted above, the TMG regime introduced the concept of "exceeding credits" for emissions reductions exceeding a baseline which credits might be transferred to a facility that has not meet its reduction obligations. ${ }^{81}$

The vision within TMG is that the TMG regime is the first of what will become a network of tier two ETSs implemented by local governments and major cities throughout Japan. These will support a first tier regime instigated by the national Government.

\subsection{Particular lessons presented by the two regimes}

Whilst an ETS is premised on a market induced reduction in emissions governments appear reluctant to completely give up control in favour of market forces. A concern with cost containment and price stability necessitates the reservation of a right to intervene and manipulate the market. Thus ETS design typically places constraints or limits on the free rein of market forces.

In the Australian context this is most readily demonstrated by the phasing in features of the regime that has seen it operate at a fixed price to date with trading due to commence from 1 July 2014. Fixing the price satisfies both the cost containment and price stability criteria whilst also allowing business and the government an opportunity to ease towards a full market regime. This was particularly important given the experience in the EU where the initial over supply of permits (partly due to the economic downturn) has collapsed the market price and damaged the environmental credentials of the ETS.

The TMG experience also illustrates the importance of a gradual lead in to implementing a full market based ETS. For almost a decade before the ETS was introduced TMG embarked on steps towards it through a carbon reduction reporting program and voluntary reductions thereby building up capacity, a knowledge base and a relationship with the entities involved. This has allowed TMG to establish both an advisory function and a certification program whereby it can reward those entities implementing exceptional energy consumption measures. ${ }^{82}$ It has been suggested that this advisory function and the certification program may be the main factors in the high level of reductions to date rather than the operation of the market. ${ }^{83}$

\footnotetext{
${ }^{81}$ Emails from Professor Satoshi Kurokawa, Professor of Environmental Law \& Administrative Law, Waseda University, School of Social Sciences dated 22 November 2012 and 4 November 2013.

${ }^{82}$ With reduced reduction targets resulting in the likelihood of excess reductions which can then be traded at a profit.

${ }^{83}$ Niederhafner 2013 at $16-22$.
} 
In addition, the TMG experience demonstrates an even greater concern to maintain some control over the market by the fact that tradable allowances are not available until TMG has itself confirmed that the required reductions have been achieved. Furthermore, the five year compliance window generates an expectation that entities should have a greater opportunity to put in place measures that will ensure the mandated reductions. The market is, thus, more a backup to permit participants to acquire allowances to avoid punishment and thereby takes a secondary role in driving emissions reductions in contrast to the Australian regime. Notably the restrictions on the generation of tradable allowances (ex ante and then only 50\% of reductions) and limits on the availability of offsets may well result in an undersupply issue in stark contrast to the EU experience, a possibility to which TMG's reservation of emergency measures is directed.

Finally, the regimes present an instructive contrast in the political economy experience. Whilst the governing party of the TMG has recently changed there has been no suggestion of a reconsideration of the ETS. This is in stark contrast to the Australian experience. One explanation could be that the gradual introduction of the ETS and TMG's advisory function ensured community consensus. Maybe Japan's unique group orientated culture is at play. The lack of divisiveness in relation to the regime is even more remarkable given that it was implemented during and following a lengthy period of economic malaise, was shortly followed by the economic and social upheaval caused by the triple disasters and the carbon price is exceptionally high on global standards.

The Australian ETS experience dates from 2007. The election campaign of November of that year saw both major parties promoting an ETS and the new prime minister referring to the need to combat climate change as the greatest moral crisis facing the country. Yet, in less than three years both parties were contesting the next election on no carbon tax/ETS platforms. The subsequent introduction of an ETS (on the insistence of the Green party on whom Labor relied after the election to retain government) was viewed by many in the community as a betrayal of the pre-election promise. A spirited destabilisation campaign by conservative, business and climate change sceptic forces, supported by the unfolding ETS debacle in Europe, the perceived intransience of other nations to adopt an ETS and a forecast decline in the country's economic performance railed against the fledgling regime. Its unpopularity was to embolden the new conservative government elected in 2013 to press the argument that it had a mandate to repeal it.

The difficulties of introducing a complicated regulatory scheme such as an ETS are well recognised. ${ }^{84}$ The unfortunate reality is that the true facts were the first casualty in the debate over the regime. The arguments about its impact on trade exposed industries ignored the copious

\footnotetext{
${ }^{84}$ Discussed and referenced in the paper by Sven Rudolph and Takeshi, “Tokyo's greenhouse gas emissions trading scheme: a model for sustainable megacity carbon markets?” available at http://ideas.repec.org/p/mar/magkse/201225.html (last visited 13 November 2012).
} 
concessions for such industries and exemption of agriculture. The arguments about the cost to the community ignored the generous compensation handed out to families and small business. The arguments that ETSs were not being adopted elsewhere ignored developments in the US, China, Korea and Japan amongst others. The argument that the carbon price was too high ignored the likely impact of linking with the EU. The argument that once linked it would encourage emissions abatement overseas but not domestically ignored the reality that emissions know no jurisdictional boundaries. The argument that it had caused a huge spike in energy costs ignored the other factors impacting on electricity prices, especially the increased expenditure on capital investment. The government had created a Climate Change Commission empowered to educate and bring the community along. Staffed with scientists and issuing complex reports on the need to address climate change, it was spectacularly unsuccessful vis-à-vis the misinformation propounded by the general media, much of which was on a mission to replace the government.

\subsection{Conclusion}

The TMG scheme has been recognised as fulfilling most of the requirements for a sustainable ETS. Whilst improvements by way of extending gas and sector coverage, tightening the caps given that much of the mandated reductions have already been met, phasing in auctions rather than grandfathering and freeing up the allowances market might be suggested, ${ }^{85}$ it is uncontested that there has been a $23 \%$ reduction in emissions by the covered entities since its inception. Given the effect of external factors, such as the economic crisis and triple disasters, as well as the lag effect of the TMG initiatives before and outside of the ETS, it is difficult to identify exactly how successful it has been. ${ }^{86}$ Certainly very few trades have occurred ${ }^{87}$ but this is likely to change as the compliance period draws to a close and, in any event, as explained above, trading may be a less integral part of the scheme than an ETS that recognises tradable permits from the date of commencement.

The legislative and administrative features of the Australian system appear similarly robust. Much would depend, though, on the level of stringency established by its emissions caps. Any continued level of assistance and concessions for some industry sectors would also be important in assessing the environmental credentials of the regime. The transition into a trading regime and, particularly, the linkage with the EU are challenges that are yet to be met and, indeed, may never be. How the environmental integrity of the Australian ETS could be quarantined from the oversupply infecting the EU regime would be a particular challenge.

\footnotetext{
${ }^{85}$ Rudolph 2012 at section 4.

${ }^{86}$ Although TMG asserts that much of the reduction is due to measures undertaken by covered entities: The Tokyo cap-and-trade program achieved 23\% reduction in the $2^{\text {nd }}$ year, TMG media release, 21 January 2013.

${ }^{87}$ Only 17 trades had occurred in the first 29 months of the commitment period: Niederhafner 2013 at 14.
} 
The philosophical difference reflected by the TMG and Australian approaches presents two options to other jurisdictions contemplating an ETS. The choice between the two centres on the primacy wished to be given to market forces and the desirability of promoting domestic reductions in emissions albeit that the marginal cost of abatement might be higher than in other jurisdictions. Thus the TMG regime seeks to impose a regulatory structure to mandate local emissions reductions with the trading mechanism secondary. The TMG regime might, therefore, be easier to promote to local constituents although businesses might see it imposing a greater cost burden than an Australian type ETS where the market is more liquid and open to foreign entrants.

Unfortunately there are unlikely to be many more lessons provided by the Australian ETS as the prospects for both regimes appear very different. Whilst the TMG regime is being promoted as a template for other jurisdictions, both within and outside Japan, and might even provide stimulus for action at the National level, the continuance of the Australian regime past 30 June 2014 looks perilous. The success or otherwise of the proposal of the new Government to repeal it rests in the hands of minority parties due to take control of the upper house after that date.

Irrespective of the short-term political outcome in Australia the global momentum is towards enacting such regimes. No doubt both the features of the TMG and Australian regimes identified in this paper will be examined by policy analysts in other countries as they embark on their ETS adventure. The need to phase the regime in gradually and bring the community along whilst maintaining greater price control (at least initially) may be particular lessons to note. 